\title{
ANTEGRADE URETEROSCOPY FOR AN OBSTRUCTING DISTAL URETERIC STONE IN A PARTIAL DUPLEX SYSTEM WITH ECTOPIC DISTAL INSERTION
}

\author{
Jonathan Manley ${ }^{1}$, Ferekh Salim², Jake Patterson ${ }^{3}$ \\ ${ }^{1}$ Department of Urology, Sheffield Teaching Hospitals NHS Foundation Trust, Sheffield, UK \\ ${ }^{2}$ Consultant Radiologist at Sheffield Teaching Hospitals Trust, Sheffield, UK. \\ ${ }^{3}$ Consultant Urological Surgeon at Sheffield Teaching Hospitals NHS Foundation Trust.
}

Corresponding author: jpmanley@doctors.org.uk

Submitted: August 3, 2019. Accepted: August 23, 2019. Published: November 15, 2019.

\begin{abstract}
Urinary tract abnormalities such as ureteric duplication and ectopic insertion may result in difficulty accessing the distal ureter to treat obstructing stones. This case illustrates the feasibility of treating distal ureteric stones with antegrade flexible ureteroscopy.
\end{abstract}

Duplication of the ureters is common, with an incidence of $0.5-3 \%$. In the duplex system, the kidney has two pyelocaliceal systems with either a single ureter, bifid ureters which coalesce before insertion or, that drain separately. Ectopic ureteral insertion is associated with ureteric duplication. In males the insertion is always supra-sphincteric, into structures derived from the Wolffian ducts; the seminal vesicle, vas deferens, ejaculatory duct or prostatic urethra. ${ }^{1,2}$

This case illustrates the difficulties of treating a distal ureteric stone in a patient with an inaccessible distal ureter due to congenital anatomical abnormalities and suggests that antegrade ureteroscopy can be performed safely for distal ureteric stones if other treatment options are not available.

\section{CASE REPORT}

A 41-year-old male attended the urology clinic with right loin pain and dysuria. He had a previous urological history of recurrent urinary tract infections and surgical repair of hypospadias as a child.
Examination showed a hypospadic meatus and the suggestion of multiple urethro-cutaneous fistulae. Urinalysis showed non-visible haematuria and pyuria whilst blood tests suggested an element of renal failure; creatinine $128 \mu \mathrm{mol} / \mathrm{L}$, eGFR $54 \mathrm{~mL} / \mathrm{min} / 1.73 \mathrm{~m}^{2}$. Flexible cystoscopy revealed multiple urethral fistulae, no intravesical ureteric orifices and likely ectopic ureteric insertion at the level of the verumontanem. A subsequent CT-urogram showed bilateral partial duplex systems, bilateral ectopic insertion of the ureters into the prostatic urethra, and bilateral distal ureteric stones (4 mm left, $8 \mathrm{~mm}$ right), and an atrophic left kidney. A DMSA renogram showed a split function of; left 22\%, right $78 \%$ (Figure 1, Figure 2, Figure 3).

Due to an episode of acute urosepsis a right-sided nephrostomy was placed. Following Multidisciplinary team reviews, it was felt that the urethral fistulae could be managed after the management of his right ureteric stone.

Prone percutaneous nephrolithotomy (30Ch Amplatz sheath) and antegrade flexible ureteroscopy (Flex XC, 
FIG. 1 CT- reconstructed anterior view of the ureteric anatomy showing partial ureteric duplication.

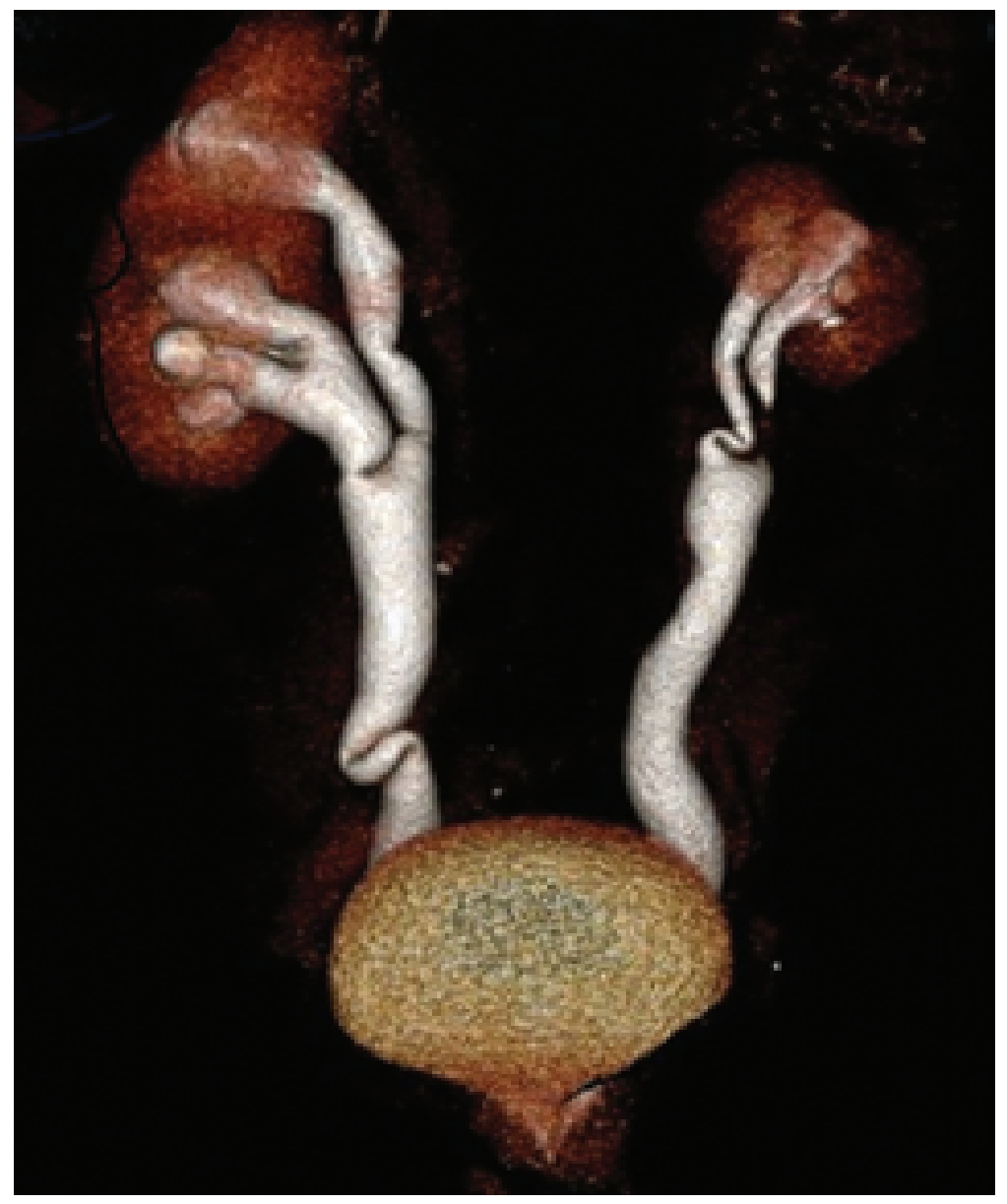

Karl Storz) was performed alongside a Sensor wire to access the distal ureter as retrograde access was not possible. The scope could not pass completely to the stone due to ureteric tortuosity, distal ectopic insertion and the antegrade access. As such a $2.4 \mathrm{Ch}$ basket (ZeroTip ${ }^{\mathrm{TM}}$, Boston Scientific) was used under combined distant vision and image intensifier guidance to remove the stone intact. A $12 \mathrm{Ch}$ non-locking nephrostomy tube was left in situ.

Post-operative nephrostogram showed prompt drainage of the right side with free flow of contrast into the prostatic urethra and his renal function improved $(\mathrm{Cr} 86 \mu \mathrm{mol} / \mathrm{L})$. Subsequent investigation revealed primary hyperparathyroidism. Despite discussion regarding re-implantation of his ureters, the patient has opted for conservative management and surveillance, including the left-sided stone.

\section{CONCLUSION}

The inaccessibility of the distal ureters in this case made for difficulties in treating the distal ureteric stone. There is a relative paucity of case reports ${ }^{3,4}$ of antegrade ureteroscopy in the adult population, particularly in the case of stones below the level of the iliac vessels. This case suggests that it may be performed safely if other treatment options are not 
FIG. 2 CT-reconstructed posterior view of the ureteric anatomy showing ectopic ureteric insertion into the prostatic urethra.

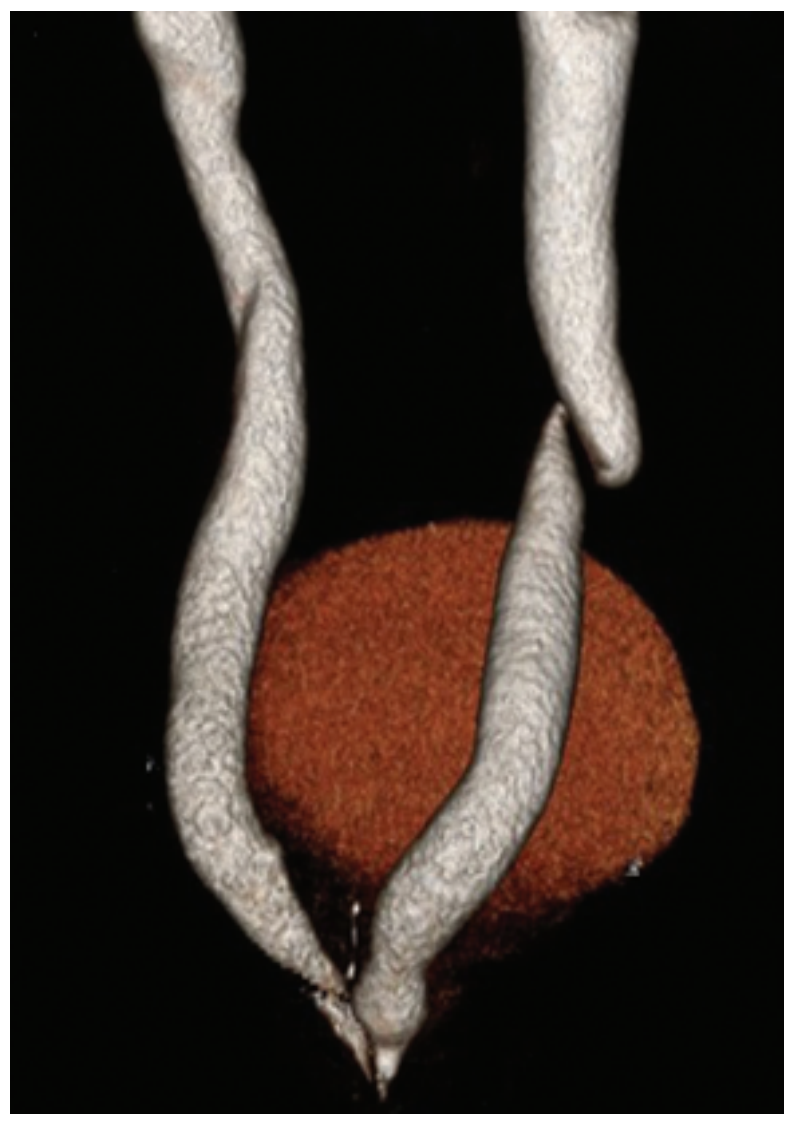

available due to anatomical variants, but awareness of the length of the ureter is important in terms of choice of technique and equipment.

\section{REFERENCES}

1. Fernbach SK, Feinstein KA, Spencer K, et al. Ureteral duplication and its complications. Radiographics 1997;17:109-27.

2. Karakose A, Aydogdu O, Atesci YZ . Unilateral complete ureteral duplication with ureteral stone: A rare entity. Can Urol Assoc J 2013;7(7-8):e511-12.
FIG. 3 CT-KUB oblique sagittal view demonstrating the distal ureteric stone with proximal hydroureterosis.

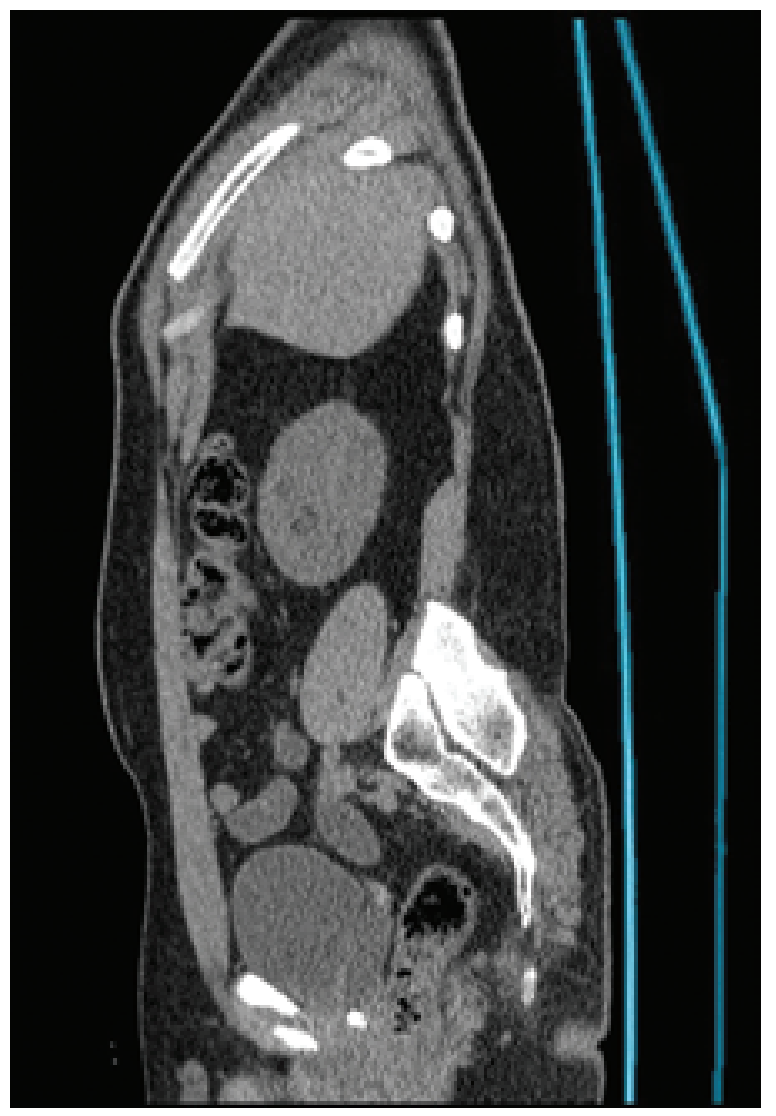

3. Caliskan S. Bilateral ureteral duplication of complete left and incomplete right side with lower pole kidney stone. J Coll Physicians Surg Pak 2017;27 (supplement 1): S65-66.

4. Scantling D. Ross C, Altman H. A 52-year-old male with bilaterally duplicated systems with obstructing ureteral stones. Curr Urol 2013;7:104-6. 